\title{
Vitamin E succinate inhibits survivin and induces apoptosis in pancreatic cancer cells
}

\author{
Dorrelyn Patacsil - Sylvester Osayi • Anh Thu Tran - Francisco Saenz • \\ Lydia Yimer - Ayesha N. Shajahan - Prafulla C. Gokhale - Mukesh Verma • \\ Robert Clarke $\cdot$ Subhash C. Chauhan · Deepak Kumar
}

Received: 19 May 2011/ Accepted: 21 July 2011/Published online: 13 August 2011

(C) Springer-Verlag 2011

\begin{abstract}
Pancreatic cancer is the fourth leading cause of cancer-related deaths in the United States. Identifying novel chemotherapeutic and chemopreventive approaches is critical in the prevention and treatment of cancers such as pancreatic cancer. Vitamin E succinate (VES) is a redox-silent analog of the fat-soluble vitamin alphatocopherol. In the present study, we explored the antiproliferative action of VES and its effects on inhibitor of apoptosis proteins in pancreatic cancer cells. We show that VES inhibits cell proliferation and induces apoptosis in pancreatic cancer cells. Further, we demonstrate that VES downregulates the expression of survivin and X-linked inhibitor of apoptosis proteins. The apoptosis induced by VES was augmented by siRNA-mediated inhibition of survivin in PANC-1 cells. In summary, our results suggest that VES targets survivin signaling and induces apoptosis in pancreatic cancer cells.
\end{abstract}

D. Patacsil - S. Osayi · A. T. Tran · F. Saenz $\cdot$ L. Yimer .

D. Kumar $(\bowtie)$

Cancer Research Laboratory, Department of Biological and Environmental Sciences, University of the District of Columbia, Building 44, Room 312, 4200 Connecticut Avenue, NW, Washington, DC 20008, USA

e-mail: dkumar@udc.edu

A. N. Shajahan - P. C. Gokhale - R. Clarke - D. Kumar Lombardi Comprehensive Cancer Center, Georgetown University, Washington, DC 20057, USA

M. Verma

Methods and Technologies Branch, Epidemiology and Genetics Research Program, Division of Cancer Control and Population Sciences, National Cancer Institute, Bethesda, MD 20892, USA

S. C. Chauhan

Cancer Biology Research Center, Sanford Research/University of South Dakota, Sioux Falls, SD 57105, USA
Keywords Vitamin E - Vitamin E succinate - Survivin · Pancreatic cancer $\cdot$ Apoptosis

\section{Introduction}

Pancreatic cancer is the fourth leading cause of cancer death with 43,140 new cases and 36,800 deaths estimated in the United States in 2010. Despite resection and adjuvant therapy attempts, patients diagnosed with pancreatic cancer continue to have a poor prognosis with a 5-year survival rate of $20 \%$ (Jemal et al. 2010). The high mortality rate for pancreatic cancer is due primarily to the advanced stage at diagnosis in the majority of cases: by the time of diagnosis, $80 \%$ of pancreatic cancers are no longer localized to the pancreas. Gemcitabine, currently the most effective chemotherapeutic drug against pancreatic cancer, results in a response rate of $24 \%$ and median survival of 5.6 months. Thus, there is a need for more effective therapeutic approaches. Dietary modulation of signaling pathways is a promising strategy for cancer prevention and treatment. Vitamin Es (VitEs) are the most potent natural antioxidant vitamins and generally include all compounds that exhibit natural vitamin E-like activity. The naturally occurring VitEs include tocopherols and tocotrienols. Alpha-tocopheryl succinate or vitamin E succinate (VES), obtained by the esterification of alpha-tocopherol, is included in the class of drugs called "mitocans" and is the most studied vitamin E compound known to reduce the growth of various cancer cells in vitro and in vivo with no effect on normal cells (Neuzil et al. 2006; Wang et al. 2006).

VES has been shown to generate anticancer activity in a wide range of solid tumors including breast, prostate, gastric, and colorectal tumors as well as in melanomas (Malafa et al. 2006; Malafa and Neitzel 2000; Neuzil 2003; 
Quin et al. 2005). VES exerts its apoptotic effect in cancer cells by various apoptotic signaling pathways. It modulates transforming growth factor-beta (TGF $\beta$ ) and Fas (CD95) apoptotic signaling pathways, thereby contributing to the activation of c-Jun N-terminal kinase (JNK)-mediated apoptosis (Kline et al. 2004). However, TGF $\beta$-independent mechanisms are also reported (Yu et al. 2002). Mitocans generate reactive oxygen species (ROS) that mediate the formation of disulfide bridges between cytosolic Bax monomers to form mitochondrial outer membrane channels. The activation of Bax channels resulting in the translocation of cytochrome $\mathrm{C}$ into the cytoplasm and activation of caspase 3 and 9 is a key event during VESinduced apoptosis (Neuzil et al. 2006). Recent studies have also suggested the potential use of VES in cancer therapy and sensitization of cancer cells to different chemotherapeutics (Tomasetti et al. 2004; Yu et al. 2002). Despite exploratory studies on the effect of VES on different cancer cells, the exact mechanism of VES-induced apoptosis remains elusive.

Fat-soluble vitamins play an important role in pancreatic cells (Ohlsson et al. 2004). Limited studies have been performed to examine the effects of vitamin $\mathrm{E}$ and its analogs in pancreatic cancer cells (Greco et al. 2010; Heisler et al. 2000; Ohlsson et al. 2004). A few studies have indicated that vitamin $\mathrm{E}$ does not inhibit the growth of pancreatic cancer cell line (Greco et al. 2010; Ohlsson et al. 2004). In another study, vitamin $E$ supplements failed to reduce tumor growth in azaserine-treated rats and $\mathrm{N}$-nitrosobis (2-oxopropyl) amine (BOP)-treated hamsters (Appel et al. 1996). Contrary to these findings, in the present study, we demonstrated that VES inhibits the growth of pancreatic cancer cells by inducing apoptosis and modulates the expression of inhibitor of apoptosis proteins (IAPs).

\section{Materials and methods}

\section{Cell culture and materials}

Human pancreatic cancer cells (PANC-1, COLO-357, and ASPC-1) were obtained from Georgetown University's tissue culture facility. All the cell lines were cultured as a monolayer in Dulbecco's modified Eagle medium (DMEM; Invitrogen, Carlsbad, CA) supplemented with 5\% heat-inactivated fetal bovine serum and $25 \mu \mathrm{g} / \mathrm{ml}$ gentamicin (Invitrogen).

The following antibodies, reagents, and chemicals were obtained commercially: vitamin E succinate (VES) and monoclonal anti- $\beta$-actin antibody (Sigma-Aldrich, St. Louis, MO); survivin antibody (Santa Cruz Biotechnology, Santa Cruz, CA); caspase-3, Cdc2, p53, p21, and cleaved
PARP antibodies (Cell Signaling Technology, Danvers, MA); horseradish peroxidase-conjugated secondary antibody (Jackson Immunoresearch Laboratories, West Grove, PA); WST-1 reagent and protease inhibitor cocktail tablets (Roche Applied Science); ECL Plus Western blotting detection system (GE Life Sciences, Piscataway, NJ); and Coomassie protein assay reagent (Pierce Thermo Scientific, Rockford, IL).

\section{Cell viability}

The effects of VES on cell viability and the proliferation of pancreatic cancer cells were determined using a cell viability detection kit (4-[3-(4-iodophenyl)-2-(4-nitrophenyl)-2H-5tetrazolio]-1, 3-benzene disulfonate, WST-1) according to the manufacturer's instructions (Roche Applied Science, Indianapolis, IN). Briefly, pancreatic cancer cells (PANC-1, COLO-357, and ASPC-1) were seeded onto 96-well plates at a density of 3,000 cells per well in complete media and treated at various concentrations and times with a vehicle (ethanol) or VES. At the end of treatment, $10 \mu \mathrm{l}$ of the WST-1 reagent was added to each well to measure cell proliferation using a plate reader (Bio-Rad Model 680) at $A=450 / 600$.

\section{Quantification of apoptosis by sub-G1 analysis}

Apoptosis was determined by the flow cytometric analysis of cells treated with VES. The cells were treated with different concentrations of VES for the indicated time. The floating and adherent cells were pooled, washed, fixed in $70 \%$ ethanol and stained with propidium iodide for FACS analysis (Becton-Dickinson, Franklin Lakes, NJ). The percentage of cells in the sub- $G_{1}$ phase was calculated using Reproman computer software and was used as an index of apoptosis as previously described (Kumar et al. 2004).

\section{Cell cycle analysis}

To determine the effect of VES on the cell cycle, pancreatic cancer cells were plated in complete medium and allowed to grow to $70-80 \%$ confluence. The cells were synchronized by serum starvation for $18 \mathrm{~h}$, treated with the indicated concentrations of VES for $24 \mathrm{~h}$, washed, fixed with $70 \%$ ethanol, stained with propidium iodide as above and analyzed by FACS. Gating was set to exclude cell debris, doublets, and clumps.

DNA fragmentation assay

COLO-357 cells were treated with VES with indicated concentrations. DNA fragmentation was analyzed using the 
Apoptotic DNA Laddering Kit (Roche Applied Science). Apoptotic DNA fragments were isolated according to the manufacturer's protocol and resolved on $2 \%$ agarose gels for visualizations of DNA ladders.

\section{Transfection with siRNA}

PANC-1 cells were plated in 6-well plates in complete medium and allowed to grow to $50 \%$ confluence. Approximately, $100 \mathrm{nM}$ survivin or control siRNA (cell signaling) was transfected using the TransIT-siQUEST (Mirus, Madison, WI) transfection reagent according to the manufacturer's protocol. At $24 \mathrm{~h}$, indicated concentrations of VES or vehicle were added to the siRNA-transfected cells. Cells were lysed at 48-h post-transfection and subjected to Western blot analysis.

\section{Western blotting}

Immunoblotting was performed essentially as described previously (Kumar et al. 2004). At indicated times after treatment with VES, adherent and floating cells were collected. Whole cell extracts (total cell homogenates) were prepared by lysing cells in radio immune precipitation assay buffer, and proteins were separated on a $4-12 \%$ gradient Tris-glycine SDS gel (Pierce). Following SDSPAGE, proteins were transferred to polyvinylidene difluoride membranes, immunoblotted and detected using ECL reagent.

\section{Statistical analyses}

All the experiments were replicated at least 3 times. The data provided are a representative of the experiments performed. A Student's $t$ test was used to analyze treated versus untreated cells. Results are expressed as averages \pm SD. $P<0.05$ is considered significant.

\section{Results}

VES inhibits the proliferation of pancreatic cancer cells

We examined the cytotoxic effects of VES on three human pancreatic cancer cell lines: PANC-1, COLO-357, and ASPC-1. In PANC-1 cells, varying concentrations of VES treatment for 24,48 , and $72 \mathrm{~h}$ resulted in $\mathrm{IC}_{50}$ values of $40.2,36.6$, and $35.06 \mu \mathrm{M}$, respectively. Similarly, the $\mathrm{IC}_{50}$ values for COLO-357 and ASPC-1 were 51.3, 39.2, and 25.1 , and $>80,48.7$, and $50 \mu \mathrm{M}$ for the 24,48 , and $72 \mathrm{~h}$ treatments, respectively (Fig. 1). The growth inhibitory effects of VES were comparable in all the cell lines tested. We further studied whether the inhibition was due to the induction of apoptosis in these cells.

\section{Induction of apoptosis by VES}

To determine whether VES induces apoptosis in pancreatic cancer cells, COLO-357 and PANC-1 cells were treated with various concentrations of VES and evaluated by different apoptotic methods. COLO-357 cells treated with 40-80 $\mu \mathrm{M}$ VES for $24 \mathrm{~h}$ exhibited reduced growth, altered cell morphology and cell death (Fig. 2a). Apoptosis was confirmed by cleaved PARP and caspase-3 (Fig. 2b, c). Additionally, internucleosomal fragmentation of DNA was evident in COLO-357 cells treated with 40 and $80 \mu \mathrm{M}$ VES (Fig. 2d). We also determined the percentage of cells in sub-G1 using FACS analysis following treatment with varying concentrations of VES. Apoptotic cells were observed to have increased from 4 to $8 \%$ compared to the

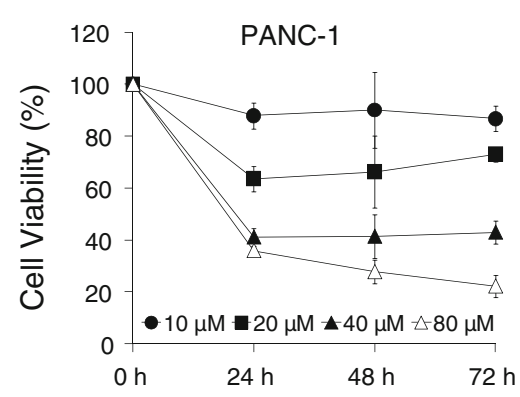

Fig. 1 VES inhibits the proliferation of COLO-357, ASPC-1, and PANC-1 pancreatic cancer cells. Cells were seeded at a density of 3,000 cells/well in a 96-well plate and treated with DMSO control or different concentrations of VES for indicated time periods. Cell proliferation was determined by WST-1 assay (Roche). The filled
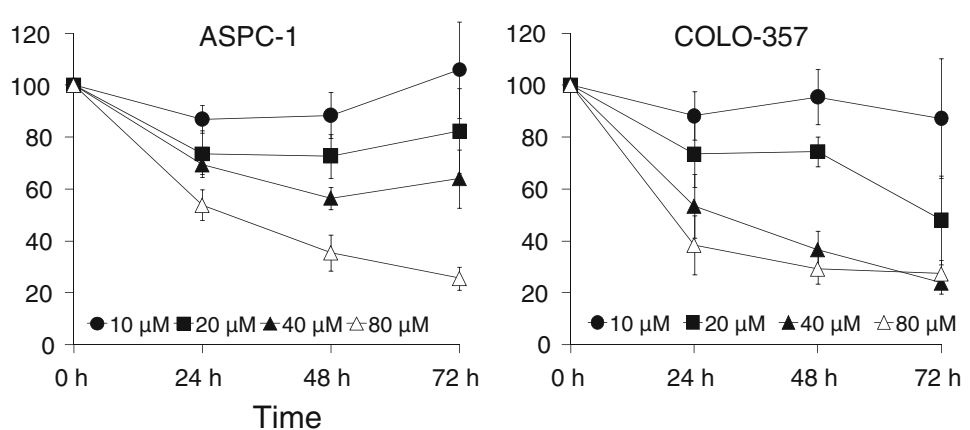

circle, square, triangle, and open triangle represent 10, 20, 40, and $80 \mu \mathrm{M}$ VES treatment, respectively. A representative of 3 experiments performed in six replicates each is shown. $P<0.05$ was considered significant 
Fig. 2 VES induces apoptosis in COLO-357 cells. a The morphology of COLO-357 cells treated with 40 and $80 \mu \mathrm{M}$ VES after $24 \mathrm{~h}$; cell shrinkage, blebs appearance. Original magnifications, $400 \times$. b and c The expression of apoptotic indicators, cleaved PARP and cleaved caspase 3, in COLO357 was determined by immunoblotting; $\beta$ actin was used as loading control. Cells were treated at various concentrations of VES $(10,20$, 40 , and $80 \mu \mathrm{M}$ ) after $24 \mathrm{~h}$. d DNA fragmentation was also examined at 40 and $80 \mu \mathrm{M}$ VES treatment for $24 \mathrm{~h}$. e Apoptosis was determined by the flow cytometric analysis of cells treated with VES at various concentrations $(10,20,40,60$, and $80 \mu \mathrm{M}$ ) for $24 \mathrm{~h}$. The percentage of cells containing sub-G $G_{1}$ DNA content was used as an index of apoptosis. $P<0.05$ was considered significant. Asterisk denotes $P<0.01$ as compared to control
A

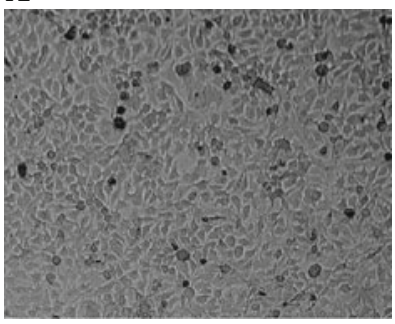

Control

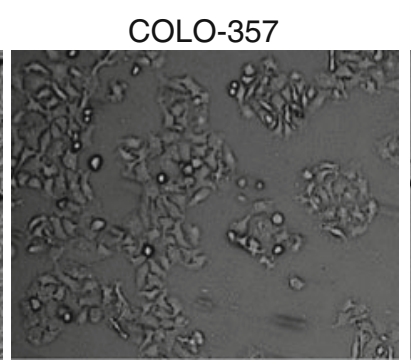

$40 \mu \mathrm{M}$ VES

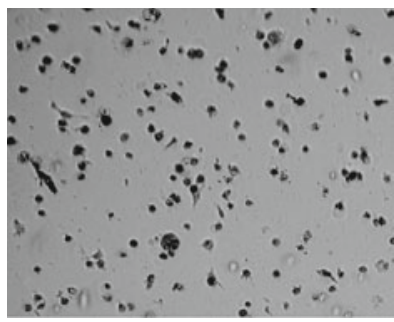

$80 \mu \mathrm{M}$ VES

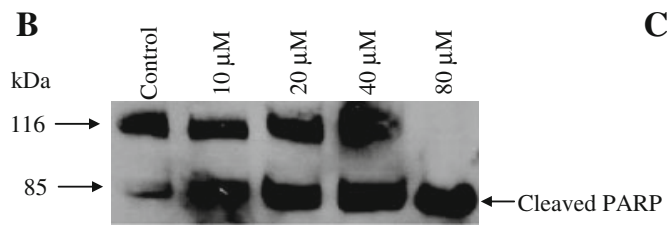

C

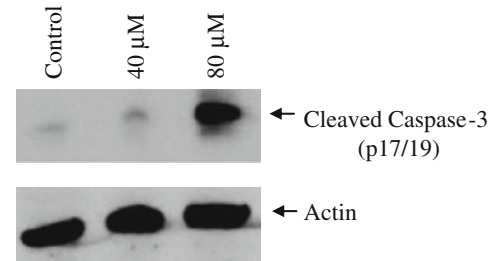

D

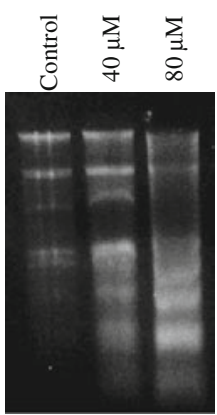

$\mathbf{E}$

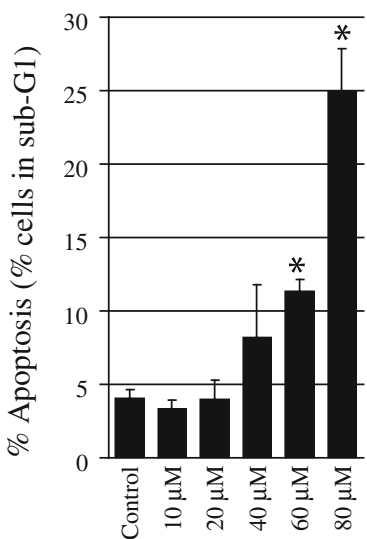

control at $40 \mu \mathrm{M}$ VES and significantly increased to $25 \%$ at $80 \mu \mathrm{M}$ VES (Fig. 2e). These data indicate that VESinduced growth inhibition in COLO-357 is due to apoptosis.

Interestingly, in PANC-1 cells, $80 \mu \mathrm{M}$ VES treatment for $24 \mathrm{~h}$ did not demonstrate apoptotic cell death. However, increasing the duration of VES treatment to 30 and $48 \mathrm{~h}$ resulted in increased apoptosis as evidenced by subG1 cells and PARP cleavage (Fig. 3). These data indicate that VES exhibits a delayed apoptotic response in PANC-1 cells as compared to COLO-357 cells.

Effects of VES on cell cycle and cell cycle-related proteins

We studied the effects of VES on the cell cycle of PANC-1 and COLO-357 cells. In PANC-1 cells, we did not observe a change in cell cycle at $24 \mathrm{~h}$ (data not shown). At $48 \mathrm{~h}$, VES induced a modest G2/M arrest along with downregulation of $\mathrm{Cdc} 2$ protein (Fig. 4a). However, in COLO-357 cells, although we did not observe any change in cell cycle after $24 \mathrm{~h}$ of VES treatment (Fig. 4b), we did observe a marked increase in $\mathrm{p} 21$ protein expression after treatment with VES. Interestingly, there was no change in the expression of $\mathrm{p} 53$ or its phosphorylation $\left(\mathrm{p} 53^{\mathrm{Ser} 15}\right)$, suggesting an alternative pathway and function for $\mathrm{p} 21$ induction (Fig. 4b).

VES inhibits the expression of inhibitor of apoptosis proteins (IAPs)

To identify possible targets for VES, we studied the effects of VES on the expression of IAPs. VES treatment of PANC-1 cells at $80 \mu \mathrm{M}$ concentration for $24 \mathrm{~h}$ resulted in the inhibition of survivin expression (Fig. 5). Similarly, we also observed the downregulation of X-linked inhibitor of apoptosis protein (XIAP) levels upon VES treatment at $80 \mu \mathrm{M}$ concentration. However, the downregulation of survivin expression was more pronounced than that of XIAP. 


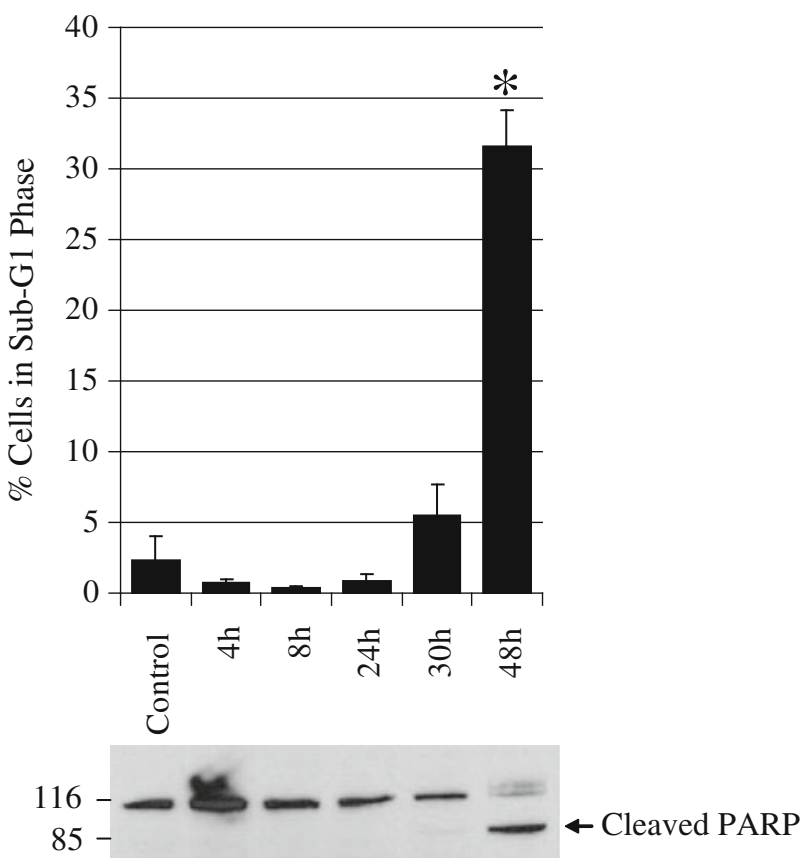

Fig. 3 VES induces apoptosis in PANC-1 cells. a Apoptosis was determined by the flow cytometry of cells treated with $80 \mu \mathrm{M}$ VES at the indicated time periods $(4,8,24,30$, and $48 \mathrm{~h})$. The percentage of cells containing sub- $\mathrm{G}_{1}$ DNA content was used as an index of apoptosis. $P<0.05$ was considered significant. Asterisk denotes $P<0.01$ as compared to control. b PARP cleavage was determined by immunoblotting

Inhibition of survivin augments VES-induced apoptosis

In earlier experiments, we observed that VES inhibits the expression of survivin in PANC-1 cells. We further analyzed whether inhibition of survivin protein expression along with VES treatment would result in increased apoptosis in PANC-1 cells. We knocked down the expression of survivin using survivin siRNA for $24 \mathrm{~h}$ followed by VES treatment for another $24 \mathrm{~h}$. As shown in Fig. 6, inhibition of survivin augmented the apoptotic effects of VES in PANC-1 cells.

\section{Discussion}

VES has been shown to have anticancer activity in breast, prostate, gastric, colorectal, and skin cancers via various apoptotic signaling pathways. Earlier studies on the effects of VES on pancreatic cancer cells have reported contradictory results (Greco et al. 2010; Heisler et al. 2000; Ohlsson et al. 2004). Ohlsson et al. (2004) found that pancreatic cell lines are insensitive to VES; however, the maximum concentration used in this study was low at $1 \mu \mathrm{M}$ (Ohlsson et al. 2004). In another recent study, Greco

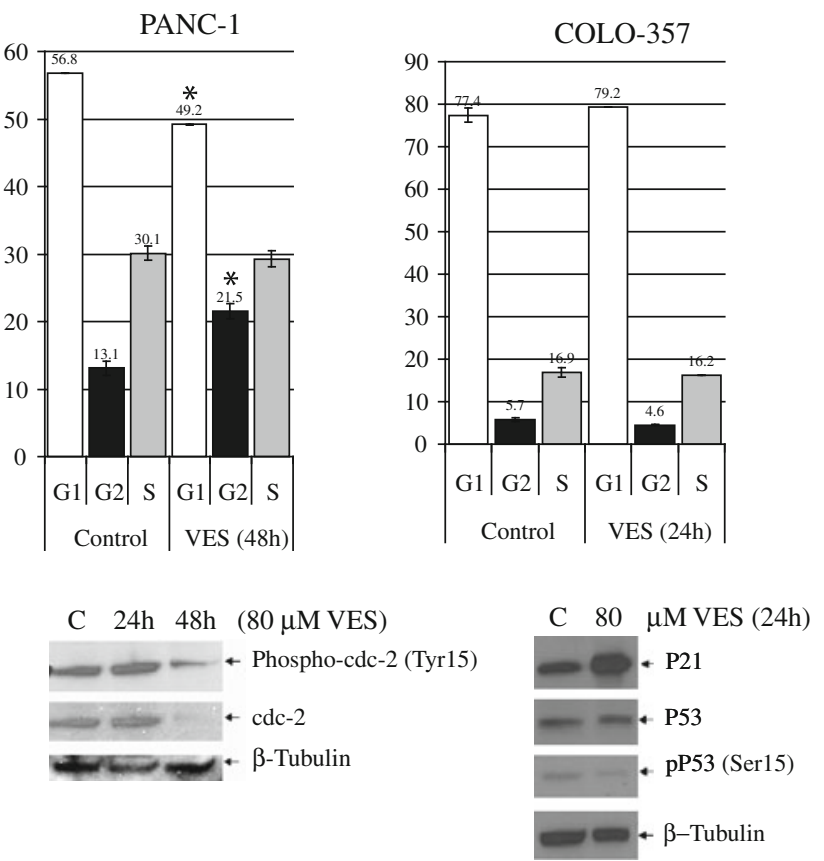

Fig. 4 VES modulates the cell cycle in PANC-1 and COLO-357 cells. a PANC-1 cells were treated with $80 \mu \mathrm{M}$ VES at $48 \mathrm{~h}$; VES induced modest $\mathrm{G} 2 / \mathrm{M}$ arrest as shown in the cell cycle accompanied by downregulation of CDC-2 after $48 \mathrm{~h}(P<0.05)$. b COLO-357 cells were treated with $80 \mu \mathrm{M}$ VES for $24 \mathrm{~h}$; there was no change in cell cycle. $P<0.05$ was considered significant. Asterisk denotes $P<0.01$ as compared to control. Expression of $\mathrm{p} 21^{\text {cip1/waf1 }}$, anti-p53, and antiphospho $\mathrm{p} 53-\mathrm{Ser}^{15}$ was determined by immunoblotting
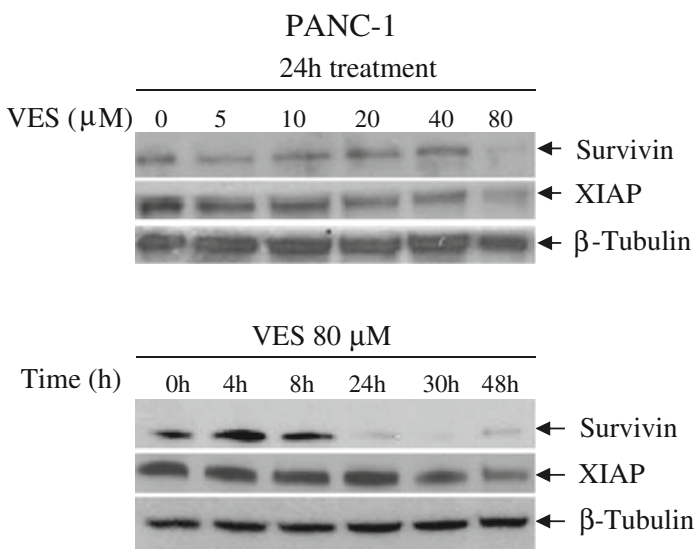

Fig. 5 VES inhibits the expression of inhibitor of apoptosis proteins (IAPS) in PANC-1 cells. PANC-1 cells were treated with VES in dose-response and time-course manner; the expression of IAPs survivin and XIAP was determined by immunoblotting

et al. (2010) studied the effects of VES on a range of pancreatic cancer cell lines and concluded that even at concentrations as high as $50 \mu \mathrm{M}$, the cell lines were not sensitive to VES. Our results differ as we demonstrated that VES at $40 \mu \mathrm{M}$ concentration not only inhibited cell proliferation but also induced apoptosis as demonstrated in COLO-357 cells. PANC-1 cells, although sensitive to VES, 


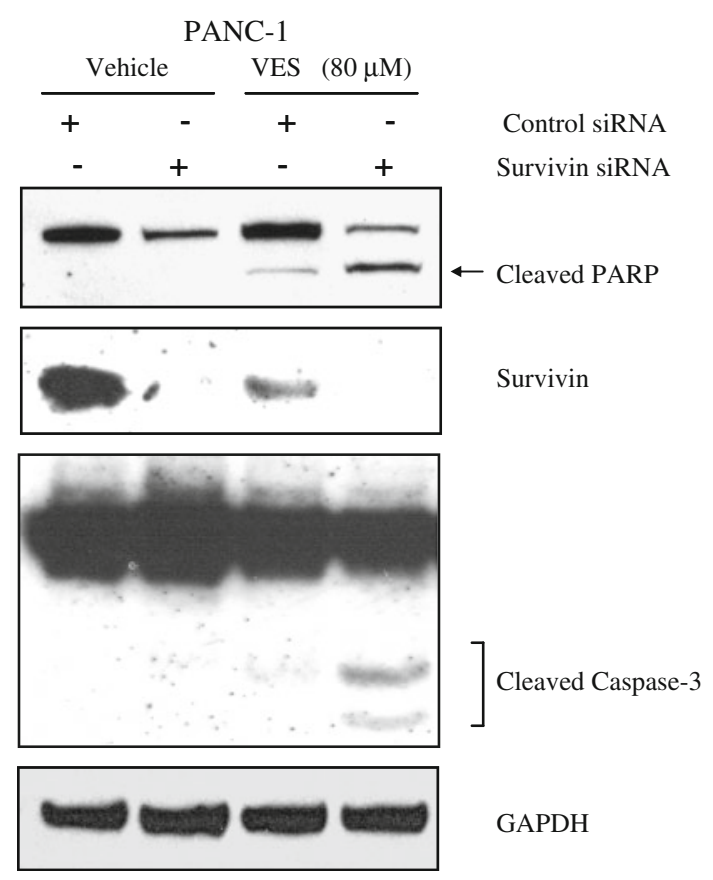

Fig. 6 Inhibition of survivin using siRNA augments VES-induced apoptosis in PANC-1. PANC-1 cells were transfected with survivin siRNA for $24 \mathrm{~h}$ and treated with $80 \mu \mathrm{M}$ VES for another $24 \mathrm{~h}$. The expression of cleaved PARP, survivin, and cleaved caspase-3 was determined by immunoblotting

did not show any apoptotic changes until 30-h incubation with $80 \mu \mathrm{M}$ VES. Greco et al. (2010) also observed mild sensitivity to VES at $100 \mu \mathrm{M}$ concentration, which was close to our apoptotic-inducing concentration in PANC-1 cells (Greco et al. 2010). Other than PANC-1, the cell lines used by Greco et al. were different than used in our study and might explain the differences in results.

We next studied cell cycle modulation by VES in COLO-357 and PANC-1 cells. In PANC-1 cells, we observed a modest G2 arrest and inhibition of cdc-2 upon treatment with VES. Cell cycle alterations by VES had been reported earlier in multiple cancer cell lines (Alleva et al. 2006; Qian et al. 1996; Yu et al. 2002). In COLO-357 cells, VES treatment did not result in any change in cell cycle; however, p53 target protein p21 was induced (Fig. 3) without any change in expression or phosphorylation $\left(\mathrm{p} 53^{\mathrm{ser} 15}\right)$ of $\mathrm{p} 53$, suggesting the presence of an alternative pathway for $\mathrm{p} 21$ induction. As of this writing, we are investigating the mechanism of p21 induction by VES and its role in VES-induced apoptosis. Investigating the mechanisms of VES-induced apoptosis, we also studied the expression of IAPs in VES-treated PANC-1 cells. IAPs prevent apoptosis by a variety of mechanisms including caspase inhibition or modulating survival pathways. $\mathrm{X}$-linked inhibitor of apoptosis (XIAP) and survivin are two members of the IAP family. We demonstrated that
VES targeted IAPs and inhibited the expression of both survivin and XIAP at $80 \mu \mathrm{M}$ VES in PANC- 1 at $24 \mathrm{~h}$ (Fig. 5). Survivin is the smallest member $(16.5 \mathrm{kDa})$ of the IAP family and is selectively expressed in most human cancers including pancreatic cancer (Altieri 2010). The expression of survivin in cancer cells has been linked to cancer cell viability and drug resistance. Because of its association with tumor growth and drug resistance, survivin has attracted growing attention as a potential target for cancer treatment. Downregulation of survivin using siRNA in pancreatic cancer cells leads to cellular apoptosis and sensitization to TRAIL and chemo- and radiotherapy (Asanuma et al. 2000; Chawla-Sarkar et al. 2004). Various strategies using genetic and pharmacologic inhibitors to inhibit antiapoptotic proteins such as IAPs, survivin, XIAP, AKT, NF-kB, Bcl-2, and MMPs have been used to sensitize cancer cells to chemotherapy and TRAIL-induced apoptosis (Chawla-Sarkar et al. 2004; Tamm et al. 1998). Similar to previous studies, we also demonstrated that inhibition of survivin potentiates VES-induced apoptosis in PANC-1 cells (Fig. 6). In summary, we have demonstrated that VES does inhibit the growth of pancreatic cancer cells by inducing apoptosis, and survivin is a possible target for VES. Additional studies in our laboratory are directed toward mechanistic insights into VES action with respect to survivin signaling.

Acknowledgments The studies were conducted using the Tissue Culture and Flow Cytometry and Cell Sorting Shared Resources of the Lombardi Comprehensive Cancer Center. We thank Karen Creswell for providing excellent technical assistance. Pilot funding from NCI UDC-LCCC U56 (DK, RC), USDA/UDC Agricultural Experiment Station (DK), MBRS SCORE/SC1 (DK), NSF-HBCU-UP fellowship (SO, AT, LY).

Conflict of interest The authors report no conflict of interest.

\section{References}

Alleva R, Benassi MS, Pazzaglia L, Tomasetti M, Gellert N, Borghi B, Neuzil J, Picci P (2006) Alpha-tocopheryl succinate alters cell cycle distribution sensitising human osteosarcoma cells to methotrexate-induced apoptosis. Cancer Lett 232:226-235

Altieri DC (2010) Survivin and IAP proteins in cell-death mechanisms. Biochem J 430:199-205

Appel MJ, van Garderen-Hoetmer A, Woutersen RA (1996) Lack of inhibitory effects of beta-carotene, vitamin $\mathrm{C}$, vitamin $\mathrm{E}$ and selenium on development of ductular adenocarcinomas in exocrine pancreas of hamsters. Cancer Lett 103:157-162

Asanuma K, Moriai R, Yajima T, Yagihashi A, Yamada M, Kobayashi D, Watanabe N (2000) Survivin as a radioresistance factor in pancreatic cancer. Jpn J Cancer Res 91:1204-1209

Chawla-Sarkar M, Bae SI, Reu FJ, Jacobs BS, Lindner DJ, Borden EC (2004) Downregulation of Bcl-2, FLIP or IAPs (XIAP and survivin) by siRNAs sensitizes resistant melanoma cells to Apo2L/TRAIL-induced apoptosis. Cell Death Differ 11:915-923 
Greco E, Basso D, Fadi E, Padoan A, Fogar P, Zambon CF, Navaglia F, Bozzato D, Moz S, Pedrazzoli S, Plebani M (2010) Analogs of vitamin $\mathrm{E}$ epitomized by alpha-tocopheryl succinate for pancreatic cancer treatment: in vitro results induce caution for in vivo applications. Pancreas 39:662-668

Heisler T, Towfigh S, Simon N, McFadden DW (2000) Peptide YY and vitamin $\mathrm{E}$ inhibit hormone-sensitive and -insensitive breast cancer cells. J Surg Res 91:9-14

Jemal A, Siegel R, Xu J, Ward E (2010) Cancer statistics, 2010. CA Cancer J Clin 60:277-300

Kline K, Yu W, Sanders BG (2004) Vitamin E and breast cancer. J Nutr 134:3458S-3462S

Kumar D, Gokhale P, Broustas C, Chakravarty D, Ahmad I, Kasid U (2004a) Expression of SCC-S2, an antiapoptotic molecule, correlates with enhanced proliferation and tumorigenicity of MDA-MB 435 cells. Oncogene 23:612-616

Kumar D, Sakabe I, Patel S, Zhang Y, Ahmad I, Gehan EA, Whiteside TL, Kasid U (2004b) SCC-112, a novel cell cycleregulated molecule, exhibits reduced expression in human renal carcinomas. Gene 328:187-196

Malafa MP, Neitzel LT (2000) Vitamin E succinate promotes breast cancer tumor dormancy. J Surg Res 93:163-170

Malafa MP, Fokum FD, Andoh J, Neitzel LT, Bandyopadhyay S, Zhan R, Iiizumi M, Furuta E, Horvath E, Watabe K (2006) Vitamin E succinate suppresses prostate tumor growth by inducing apoptosis. Int J Cancer 118:2441-2447

Neuzil J (2003) Vitamin E succinate and cancer treatment: a vitamin $\mathrm{E}$ prototype for selective antitumour activity. $\mathrm{Br} \mathrm{J}$ Cancer 89:1822-1826
Neuzil J, Wang XF, Dong LF, Low P, Ralph SJ (2006) Molecular mechanism of 'mitocan'-induced apoptosis in cancer cells epitomizes the multiple roles of reactive oxygen species and Bcl-2 family proteins. FEBS Lett 580:5125-5129

Ohlsson B, Albrechtsson E, Axelson J (2004) Vitamins A and D but not $\mathrm{E}$ and $\mathrm{K}$ decreased the cell number in human pancreatic cancer cell lines. Scand J Gastroenterol 39:882-885

Qian M, Sanders BG, Kline K (1996) RRR-alpha-tocopheryl succinate induces apoptosis in avian retrovirus-transformed lymphoid cells. Nutr Cancer 25:9-26

Quin J, Engle D, Litwiller A, Peralta E, Grasch A, Boley T, Hazelrigg S (2005) Vitamin E succinate decreases lung cancer tumor growth in mice. J Surg Res 127:139-143

Tamm I, Wang Y, Sausville E, Scudiero DA, Vigna N, Oltersdorf T, Reed JC (1998) IAP-family protein survivin inhibits caspase activity and apoptosis induced by Fas (CD95), Bax, caspases, and anticancer drugs. Cancer Res 58:5315-5320

Tomasetti M, Rippo MR, Alleva R, Moretti S, Andera L, Neuzil J, Procopio A (2004) Alpha-tocopheryl succinate and TRAIL selectively synergise in induction of apoptosis in human malignant mesothelioma cells. Br J Cancer 90:1644-1653

Wang XF, Dong L, Zhao Y, Tomasetti M, Wu K, Neuzil J (2006) Vitamin $\mathrm{E}$ analogues as anticancer agents: lessons from studies with alpha-tocopheryl succinate. Mol Nutr Food Res 50:675-685

Yu W, Sanders BG, Kline K (2002) RRR-alpha-tocopheryl succinate induction of DNA synthesis arrest of human MDA-MB-435 cells involves TGF-beta-independent activation of p21Waf1/Cip1. Nutr Cancer 43:227-236 